\title{
A Produção Científica em Saúde Coletiva (1994-1995)
}

\author{
Madel T. Luz
}

Resumo: O trabalho avalia a produção científica docente e parte da produção discente no âmbito da Saúde Coletiva, para o biênio 1994/5. São discutidas as especificidades das áreas de Ciências Humanas, Epidemiologia e Planejamento \& Administração em Saúde quanto à natureza da produção, critérios de autoria e veículos utilizados para a difusão do conhecimento. O trabalho utiliza basicamente a base de dados da CAPES referente aos cursos de Pós-Graduação na área (EXECAPES), acrescentando novos itens (como relatórios, apresentações em Congresso e publicações no prelo). Tematizou-se também, além de proceder a uma quantificação preliminar, áreas emergentes do conhecimento no âmbito da Saúde Coletiva.

Palavras-chave: Avaliação da produção científica; Banco de dados EXECAPES; Cientometria; PósGraduação em Saúde Coletiva; Características das subáreas da Saúde Coletiva.

Summary: The present paper evaluates the scientific production by researchers and Post-Graduation faculty as well as part of the scientific output by Post-Graduation students in the realm of Collective Health, for the biennial 1994/5. It discusses also the specificities of the different subareas, e.g. Human Sciences; Epidemiology; Planning \& Administration applied to Health concerning the nature of scientific output, authorship and media employed in the diffusion of the knowledge. The analysis employed basically the data summarized by a Brazilian Post-Graduation Agency (CAPES), the EXECAPES database, plus three complementary items: Scientific reports to funding agencies; presentations in Congresses and "in press" publications. Emergent areas of knowledge in the realm of Collective Health were also addressed, and a preliminary quantification of them was sketched.

Keywords: Evaluation of scientific production; EXECAPES database; Scientometrics; Pos-Graduation in the field of Collective Health; Profile of the different subareas in the field of Collective Health

1 Professora Titular do Instituto de Medicina Social / UERJ. O texto contou com a colaboração de Florin de Esteves, Mestre em Ciências Sociais pelá FCSS/UFRJ, responsável pelo levantamento e tabulação de dados. 


\section{Apresentação}

O campo da Saúde Coletiva é um campo multidisciplinar da área das Ciências da Saúde (ou campo biomédico, em conceituação tradicional), de constituição relativamente recente, de pouco mais de uma década. Este campo vem apresentando um crescimento vigoroso, no que concerne à criação de novos programas stricto sensu e à produção científica, tanto de docentes quanto de alunos (teses e dissertações, apresentações e comunicações em Congressos, artigos em revistas nacionais). Evidentemente, a escala de dois anos é muito curta para uma avaliação precisa deste crescimento, sobretudo porque há uma defasagem considerável entre a produção científica e seu registro no sistema, devido ao tempo que levam os docentes para declarar sua produção. Entretanto, os dadosresumo dos programas relativos aos últimos seis anos do sistema de registro EXECAPES (1995) permitem fazer esta ilação.
Em termos de teses e dissertações (produção discente) e de livros nacionais, artigos e capítulos de livros (produção docente), esta tendência ascencional é confirmada no biênio 94-95 (Ver Quadros 1, 2 e 3, e Gráfico 1).

Compõem o campo da Saúde Coletiva disciplinas clássicas da Saúde Pública, como a Epidemiologia, em menor escala a Administração e o Planejamento de Serviços de Saúde e, mais recentemente, disciplinas ligadas às Ciências Humanas e Sociais, como a Psicanálise e a Psicologia (configurando uma subárea de "Saúde Mental"); também a História, a Política, a Economia, a Demografia, as pioneiras Sociologia e Antropologia (antes conhecidas respectivamente como sociologia e antropologia médicas) e a Filosofia. Além disso, novas disciplinas vêm se agregando ao campo, sempre tematizando a questão da saúde em uma perspectiva social, isto é, do coletivo: a Nutrição, ou Nutrologia, a Ecologia, a Bioética, entre outras; seu perfil emerge na produção recente do campo.

\begin{tabular}{|r|r|r|r|r|r|r|r|r|r|}
\hline \multicolumn{10}{|c|}{ Quadro 1 } \\
\hline & CG Nac. & CG Int. & Liv. País & Liv. Ext. & $\begin{array}{c}\text { Art. Cap. } \\
\text { Nac. }\end{array}$ & $\begin{array}{c}\text { Art. Cap. } \\
\text { Int. }\end{array}$ & Outras & Relat. & Total \\
\hline \multirow{3}{*}{1990} & 137 & 26 & 15 & 2 & 167 & 39 & 84 & 23 & 493 \\
& $27,8 \%$ & $5,3 \%$ & $3,0 \%$ & $0,4 \%$ & $33,9 \%$ & $7,9 \%$ & $17,0 \%$ & $4,7 \%$ & $100,0 \%$ \\
\hline \multirow{2}{*}{1991} & 97 & 35 & 14 & 5 & 247 & 44 & 53 & 12 & 507 \\
& $19,1 \%$ & $6,9 \%$ & $2,8 \%$ & $1,0 \%$ & $48,7 \%$ & $8,7 \%$ & $10,5 \%$ & $2,4 \%$ & $100,0 \%$ \\
\hline \multirow{2}{*}{1992} & 230 & 29 & 24 & 7 & 336 & 71 & 70 & 9 & 776 \\
& $29,6 \%$ & $3,7 \%$ & $3,1 \%$ & $0,9 \%$ & $43,3 \%$ & $9,1 \%$ & $9,0 \%$ & $1,2 \%$ & $100,0 \%$ \\
\hline \multirow{2}{*}{1993} & 258 & 55 & 23 & 5 & 360 & 78 & 104 & 8 & 891 \\
& $29,0 \%$ & $6,2 \%$ & $2,6 \%$ & $0,6 \%$ & $40,4 \%$ & $8,8 \%$ & $11,7 \%$ & $0,9 \%$ & $100,0 \%$ \\
\hline \multirow{2}{*}{1994} & 324 & 104 & 37 & 1 & 313 & 89 & 74 & 25 & 967 \\
& $33,5 \%$ & $10,8 \%$ & $3,8 \%$ & $0,1 \%$ & $32,4 \%$ & $9,2 \%$ & $7,7 \%$ & $2,6 \%$ & $100,0 \%$ \\
\hline \multirow{2}{*}{1995} & 436 & 169 & 55 & 4 & 409 & 112 & 53 & 21 & 1259 \\
& $34,6 \%$ & $13,4 \%$ & $4,4 \%$ & $0,3 \%$ & $32,5 \%$ & $8,9 \%$ & $4,2 \%$ & $1,7 \%$ & $100,0 \%$ \\
\hline \multirow{2}{*}{ Total } & 1482 & 418 & 168 & 24 & 1832 & 433 & 438 & 98 & 4893 \\
& $30,2 \%$ & $8,5 \%$ & $3,4 \%$ & $0,5 \%$ & $37,3 \%$ & $8,8 \%$ & $8,9 \%$ & $2,4 \%$ & $100,0 \%$ \\
\hline
\end{tabular}

Art.=Artigo; Cap.=Capítulo; CG=Congresso; Ext.=Exterior; Int.=Internacional; Liv.=Livro; Nac.=Nacional; Relat.=Relatório 


\begin{tabular}{|l|rr|r|}
\hline \multicolumn{4}{|c|}{$\begin{array}{c}\text { Quadro 2 } \\
\text { Saúde Coletiva - Totais da Produção Científica do Corpo Docente 1994/1995, } \\
\text { segundo Indicadores }\end{array}$} \\
\hline \multicolumn{1}{|c|}{ Produção } & 1994 & 1995 & Total \\
\hline Artigos em revistas e capítulos de livros no País & 312 & 355 & 667 \\
\hline Artigos em revistas e capítulos de livros no Exterior & 80 & 97 & 177 \\
\hline Livros no País & 37 & 48 & 85 \\
\hline Livros no Exterior & 1 & 13 & 14 \\
\hline Trabalhos comp. em Congressos Nacionais & 68 & 33 & 101 \\
\hline Trabalhos comp. em Congressos Internacionais & 16 & 5 & 21 \\
\hline Resumos em Congressos Nacionais & 240 & 368 & 608 \\
\hline Resumos em Congressos Internacionais & 89 & 130 & 219 \\
\hline Publicações no prelo & 32 & 127 & 159 \\
\hline Relatórios de Pesquisa & 22 & 30 & 52 \\
\hline Conferências & 29 & 55 & 84 \\
\hline Totais & 926 & 1261 & 2187 \\
\hline
\end{tabular}

Por falta de melhor classificação, e devido à sua incipiente representatividade, incluímo-las na rubrica "Outros" (ver Quadros 10 e 11). Classificamos a produção do campo em três grandes subáreas principais referidas à saúde: Ciências Humanas, Planejamento e Administração em Saúde e Epidemiologia, que são as principais áreas de concentração dos Programas de Pós-Graduação, agrupando as novas disciplinas já mencionadas em Outros. Tais disciplinas começam a originar áreas de concentração em mestrado e doutorado.

Considerando-se a grande diversidade de linhas e projetos de pesquisa em atividade, resultado do conjunto de disciplinas que coexistem no campo, da orientação acentuadamente especializante dos programas, em direção às subáreas, e a interdisciplinaridade no interior das subáreas, estabelecemos um esboço classificatório temático dessas atividades, certamente sujeito à precisão ulterior, em ajustes progressivos às transformações que de fato acontecem na "ponta de linha" do processo de produção científica da Saúde Coletiva.
A classificação dos temas tomou como base as três grandes subáreas do campo, mais a rubrica "Outros". Esta classificação visa apresentar um "retrato instantâneo" do perfil atual da produção científica, considerando-se as especificidades dos programas, suas tradições, e a própria tradição produtiva das subáreas. Embora não se possa fazer inferências quanto à evolução, certos traços notáveis do "retrato" merecem ser sublinhados, notadamente no que concerne às tendências de produção das subáreas. Evidentemente, neste retrato privilegiamos as subáreas, e não os Programas e Cursos, face ao objetivo mais amplo da auto-avaliação, isto é, o próprio campo da Saúde Coletiva.

A produção 1994-95 foi, portanto, agrupada por Programas em três subáreas básicas, por indicadores de produção (docente e discente) e por ano (1994 e 1995), de acordo com o Sistema EXECAPES, estabelecendo-se os totais dos indicadores do biênio referentes a Programas, subáreas, e ao Campo da Saúde Coletiva (Quadros 4 a 9). Aos indicadores da produção científica em sentido es- 


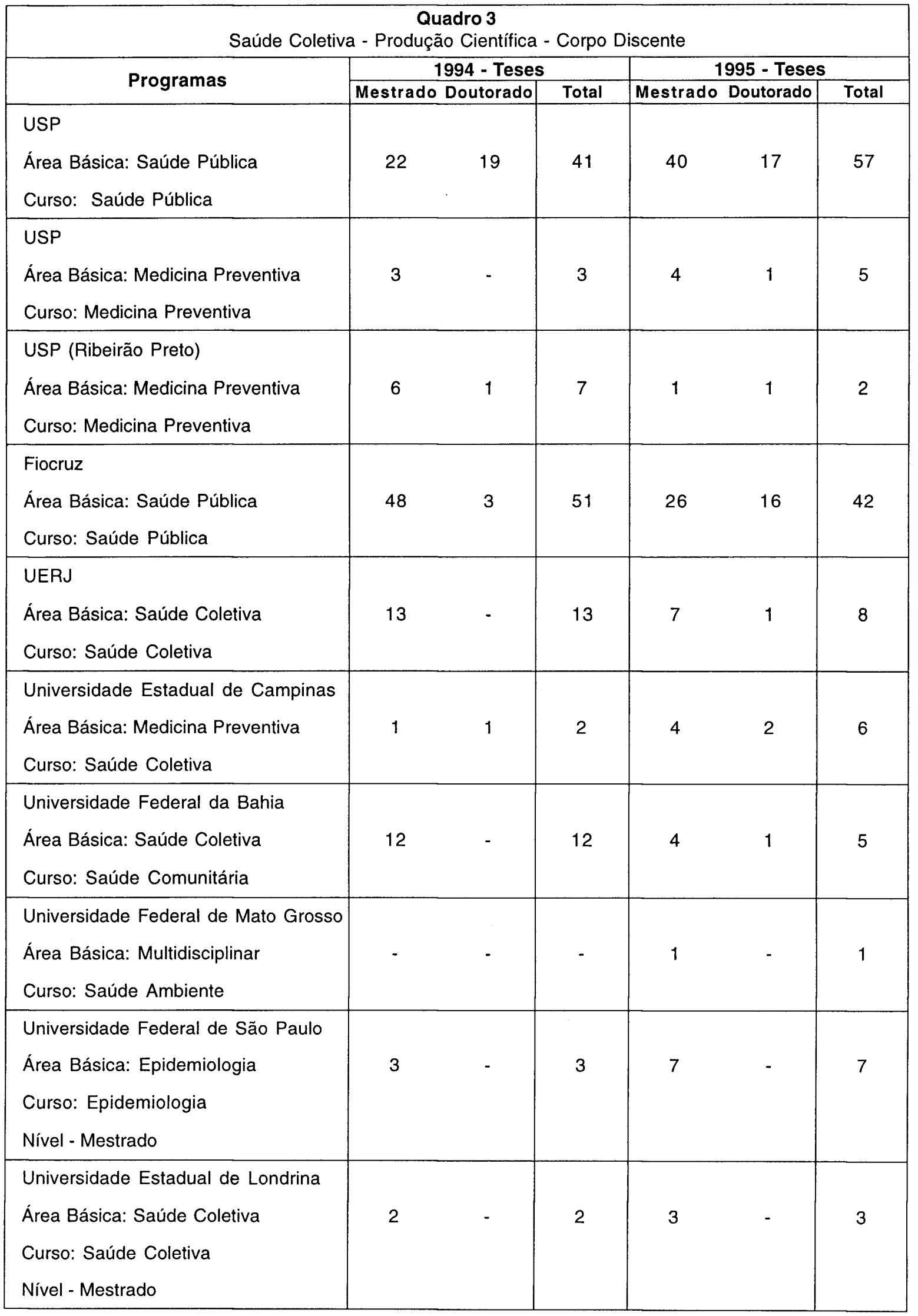




\begin{tabular}{|c|c|c|c|c|c|c|}
\hline $\begin{array}{l}\text { UFMG } \\
\text { Área Básica: Saúde Pública } \\
\text { Curso: Saúde Pública } \\
\text { Nível - Mestrado }\end{array}$ & - & - & - & 3 & - & 3 \\
\hline $\begin{array}{l}\text { Universidade Federal do Ceará } \\
\text { Área Básica: Saúde Pública } \\
\text { Curso: Saúde Pública } \\
\text { Nível - Mestrado }\end{array}$ & - & - & - & $\cdot$ & - & - \\
\hline $\begin{array}{l}\text { Universidade Estadual do Ceará } \\
\text { Área Básica: Saúde Coletiva } \\
\text { Curso: Saúde Pública } \\
\text { Nível - Mestrado }\end{array}$ & - & - & - & - & - & - \\
\hline $\begin{array}{l}\text { Univ. Federal de Mato Grosso do Sul } \\
\text { Área Básica: Saúde Coletiva } \\
\text { Curso: Saúde Coletiva } \\
\text { Nível - Mestrado }\end{array}$ & - & - & - & 5 & - & 5 \\
\hline $\begin{array}{l}\text { Fiocruz } \\
\text { Área Básica: Saúde Pública } \\
\text { Curso: Saúde da Criança } \\
\text { Nível - Mestrado }\end{array}$ & 7 & - & 7 & 9 & $\cdot$ & 9 \\
\hline $\begin{array}{l}\text { Inst. Materno-Infantil de Pernambuco } \\
\text { Área Básica: Multidisciplinar } \\
\text { Curso: Saúde Materno-Infantil } \\
\text { Nível - Mestrado }\end{array}$ & - & - & - & 3 & - & 3 \\
\hline & 117 & 24 & 141 & 117 & 39 & 156 \\
\hline \multicolumn{2}{|l|}{ Total de Teses de M/D - 1994} & \multicolumn{5}{|l|}{141} \\
\hline \multicolumn{2}{|l|}{ Total de Teses de M/D - 1995} & \multicolumn{5}{|c|}{156} \\
\hline \multicolumn{7}{|c|}{ Totais da Produção Científica - Corpo Discente - 1994-1995 } \\
\hline \multicolumn{2}{|c|}{ Total de Dissertações de Mestrado - 1994-1995 } & \multicolumn{5}{|c|}{234} \\
\hline Total de Teses de Doutorado - 1994-1 & & 63 & & & & \\
\hline
\end{tabular}




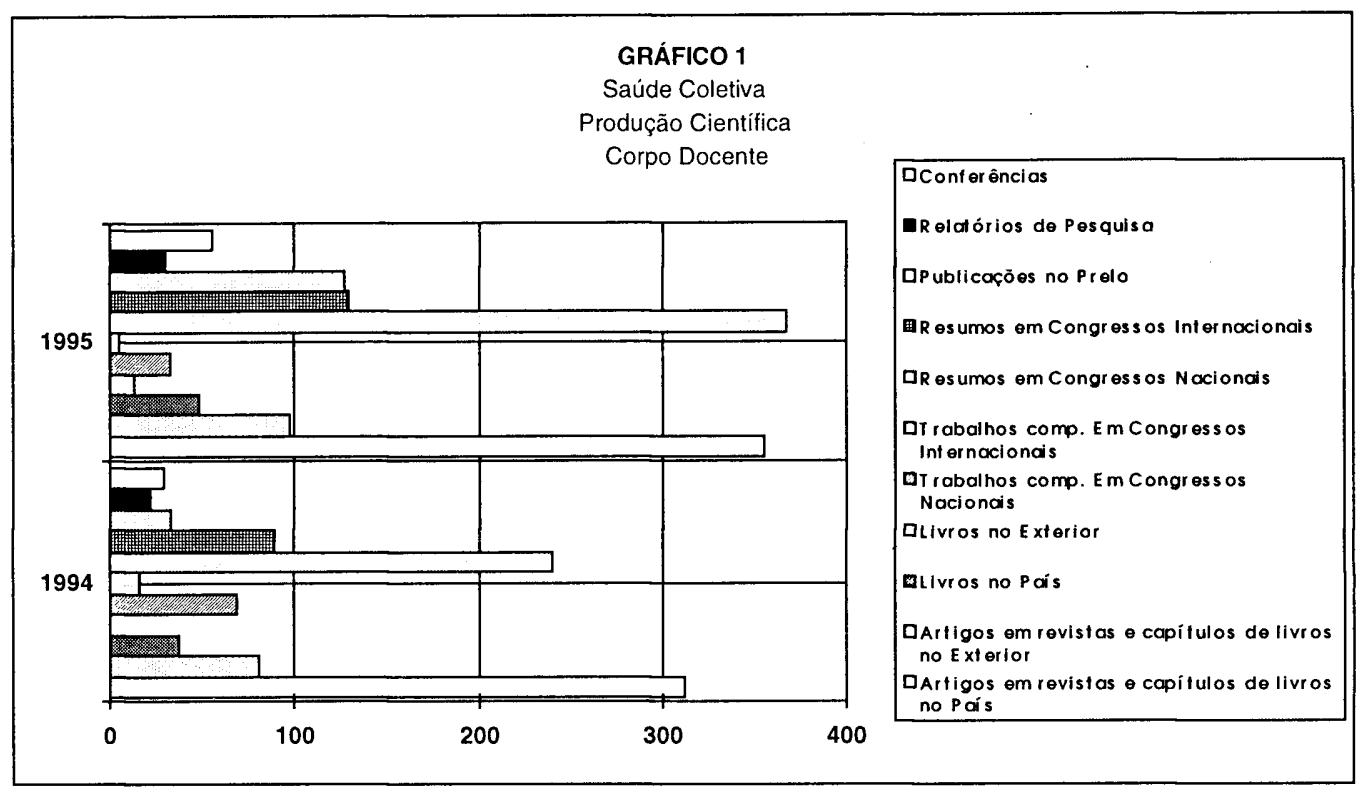

trito utilizados pela CAPES (Artigos em revistas e capítulos de livros no país; artigos em revistas e capítulos de livros no exterior; livros no país; livros no exterior; trabalhos em congressos nacionais; trabalhos em congressos internacionais; resumos em congressos nacionais; resumos em congressos internacionais), acrescentamos outros três, que consideramos bastante representativos da produção científica docente no campo da Saúde Coletiva. A difusão dessa produção é mais restrita (é preciso, aliás, não identificar produção e difusão científica, para evitar distorções na avaliação objetiva da produção docente): relatórios de pesquisa, sobretudo de projetos financiados pelas agências centrais e estaduais de fomento à pesquisa; conferências realizadas pelos docentes em congressos e seminários nacionais e internacionais; publicações no prelo. Normalmente, os relatórios e as conferências são momentos nobres da produção científica, e não cremos ser adequado inseri-los nas categorias "produção técnica" ou "produção artística", uma vez que essas categorias são (injustamente, aliás) avaliadas com menor peso na rubrica geral denominada Produção Intelectual.

Além disso, tentamos contabilizar, na medicla do possível, a produção discente relati- va aos indicadores mencionados, que se aplicam normalmente aos docentes. Como a rubrica "Produção Discente" contempla apenas "teses e dissertações", torna-se difícil avaliar e enquadrar essa produção, crescente, aliás, embora seguramente sub-registrada. Incluímola apenas quando associada à produção docente (caso de artigos e comunicações em congressos), geralmente relatada nos formulários $F, H$ e $I$ do programa de avaliação da CAPES. Seria importante, entretanto, estender com sistematicidade os indicadores da produçâo docente à produção discente, no sentido de retratar a possível vitalidade das áreas de concentração, através de suas linhas de pesquisa, e sua capacidade de inserção e formação de mestrandos e cloutorandos através das mesmas. Os programas, por sua vez, teriam de agilizar formas de participação e de registro dessa produção, por intermédio de cursos e linhas de pesquisa conduzidos pelos doutores.

Uma observação que merece ser feita concerne à sensibilidade dos atuais indicadores para aferir adequadamente a diversidade de produção do campo. De fato, os indicadores privilegiados, isto é, sobretudo os artigos publicados em revistas especializadas (nacionais, sobretudo internacionais) e 
capítulos de livros, ou livros, seguem o modelo vigente de difusão científica descle o século XIX. No final deste século e do milênio, com a revolução eletrônica na comunicação, é de se supor que em muito pouco tempo as formas de difusão da produção científica sejam também transformadas, como de fato já o vêm sendo.

Pudemos constatar que vários programas do campo da Saúde Coletiva, sobretudo os mais avançados e conceituados, estão ligados em redes de comunicação na área das ciências da vida, com seus docentes pesquisadores apresentando e intercambiando, por via informatizada, resultados de pesquisa e artigos. Por esta via, artigos estão sendo quase que automaticamente incluídos em bibliografias nacionais, e mesmo internacionais, de diversas disciplinas, e a antiga pesquisa de biblioteca é um passo posterior na revisão bibliográfica de qualquer projeto, suposta uma prévia triagem, aliás muito mais atualizada que as possibilidades cle uma biblioteca tradicional.

Brevemente, sob pena de permanecer num patamar arcaico de avaliação da produção, incapaz de acompanhar o avanço do campo, a produção assim clifundida terá de dispor de indicadores adequados para sua aferição. Para isto, a classificação hierárquica também herdada do século passado, em que "produção artística" e "produção técnica" aparecem como produtos inferiores, terá de ser superada, num momento em que ciência, arte e tecnologia se reúnem em um movimento único de produção do conhecimento, respeitadas as distinções de linguagem e de método.

\section{Resultados}

Deve ser destacada, em primeiro lugar, a especificidade de expressão das clistintas subáreas incluídas no campo da Saúde Coletiva, que se refletem nas suas respectivas estratégias de produção científica.
As ciências humanas da área de Saúde, por exemplo, historicamente marcadas pela pesquisa qualitativa e pela linguagem literária, produzem preferencialmente capítulos de livros e livros, embora os artigos em revistas nacionais venham crescendo acentuadamente, superando mesmo a habitual produção de capítulos de livros no biênio 1994-95 e superando, no total de artigos e capítulos, a tradicional área de Epidemiologia (285 contra 264, ver quadros 5 e 7, respectivamente).

Deve ser ressaltado ainda que, além da questão da linguagem e do método, há diferenças nas tradições de condução da pesquisa. Uma pesquisa social não é, evidentemente, uma pesquisa de laboratório, mas isto não é facilmente assimilável pela área biomédica, da qual a Saúde Coletiva é tributária. A distribuição de tarefas nos projetos desta área tende a obedecer a uma lógica da divisão do trabalho parcelado das atividades de pesquisa, que é corrente nas pesquisas quantitativas desenvolvidas na área médica ou epidemiológica.

Por outro lado, um recorte de objeto de dissertação de mestrado ou de tese de doutorado, numa linha de pesquisa dirigida por um docente da área de Ciências Humanas, exige, muitas vezes, uma operação metodológica diferente das estratégias das subáreas de Planejamento \& Administração e Epidemiologia. A divisão do trabalho coletivo nas ativiclades de pesquisa é também de uma complexidade diferente, e a autoria de textos não possui a mesma dinâmica que tem a área biomédica. Nesta subárea, mais estreitamente ligada à tradição biomédica, a presença de um coordenador, seguida dos nomes dos vários participantes em uma experiência, é um hábito. A co-autoria e a originalidade na produção científica obedecem a tradições completamente diferentes de acordo com as áreas em questão.

No entanto, a subárea de Ciências Humanas parece estar se integrando aos critérios estabelecidos no Campo da Saúde Cole- 


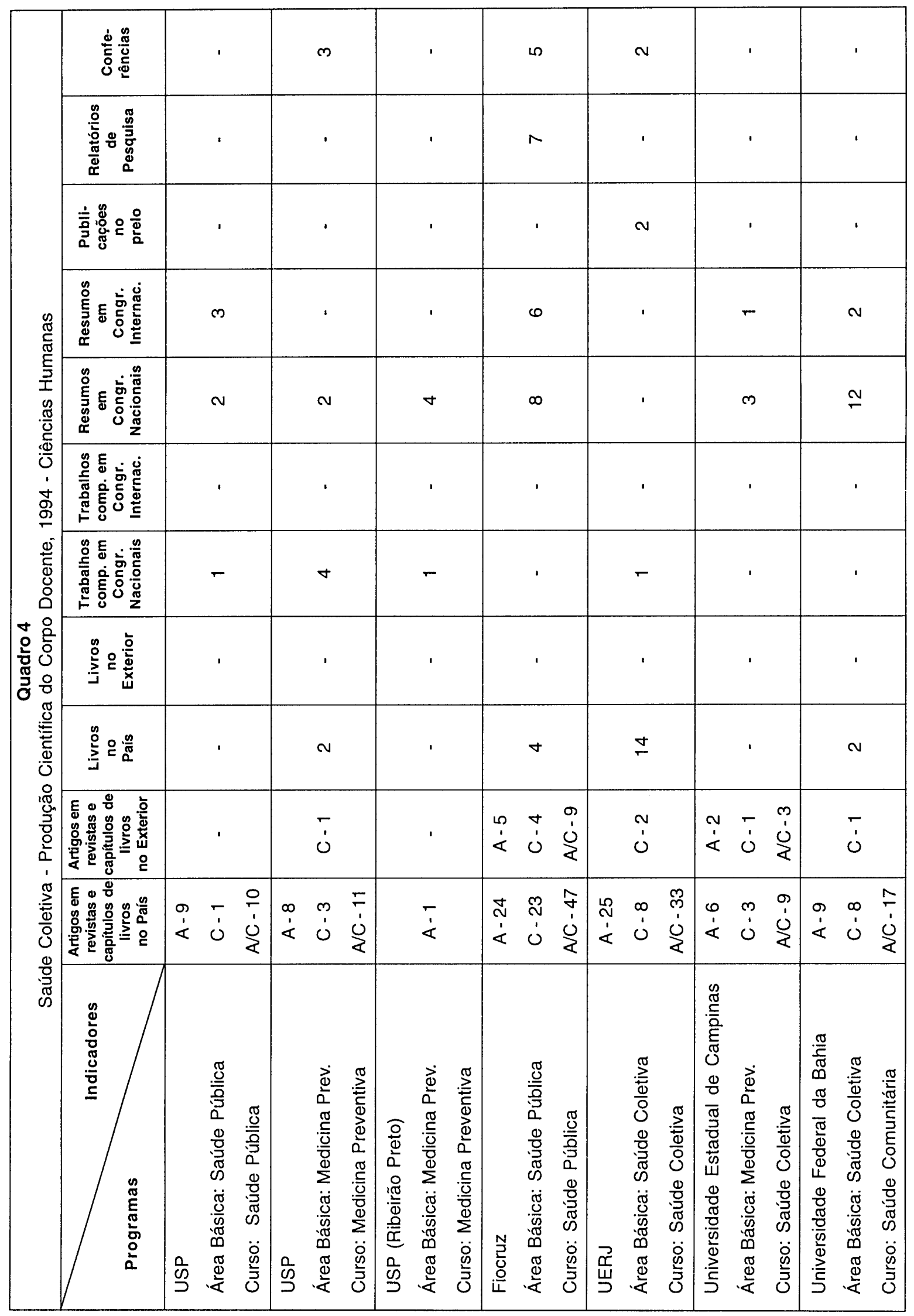




\begin{tabular}{|c|c|c|c|c|c|c|c|c|c|}
\hline ' & ' & & $\forall$ & ' & ' & . & ' & & $\underset{\nabla}{ }$ \\
\hline ' & ' & ' & ' & ' & ' & N & ' & & $\sigma$ \\
\hline ' & ' & $m$ & $n$ & ' & ' & ' & - & ' & $\mp$ \\
\hline ' & ' & $\sim$ & $\sim$ & $r$ & ' & ' & ' & ' & $\underline{\tau}$ \\
\hline ' & $N$ & 0 & $\tau$ & $\infty$ & n & 으 & ' & . & 8 \\
\hline ' & ' & ' & ' & ' & ' & ' & ' & ' & ' \\
\hline ' & - & ' & ' & ' & - & ' & $\nabla$ & . & $\stackrel{m}{-}$ \\
\hline ' & ' & ' & ' & ' & ' & ' & ' & ' & ' \\
\hline ' & ' & ' & ' & - & ' & ' & - & ' & $\stackrel{\stackrel{N}{N}}{ }$ \\
\hline & ' & $\bar{s}$ & ' & $\bar{c}$ & ' & ' & ' & & $\stackrel{\infty}{-}$ \\
\hline ' & ' & ' & ' & $\dot{u}$ & $\overline{1}$ & ' & $\begin{array}{l}N \\
\stackrel{1}{<}\end{array}$ & ' & 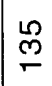 \\
\hline 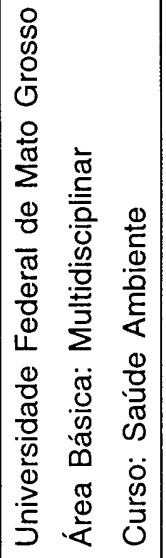 & 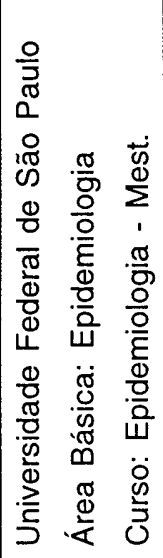 & 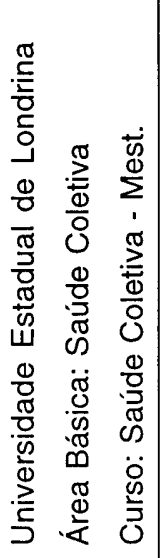 & 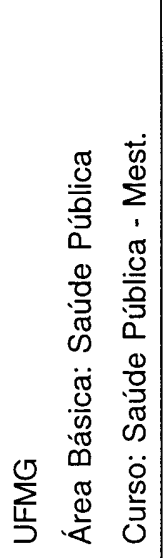 & 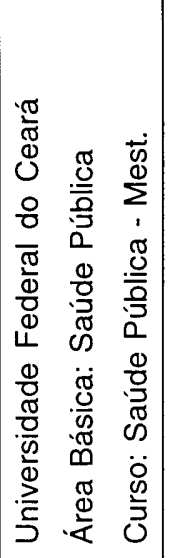 & 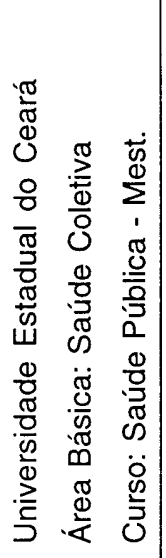 & 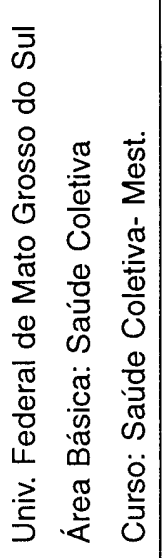 & 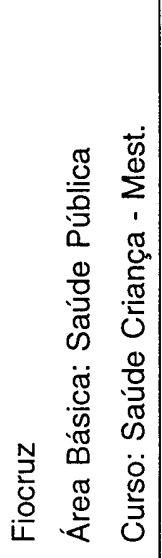 & 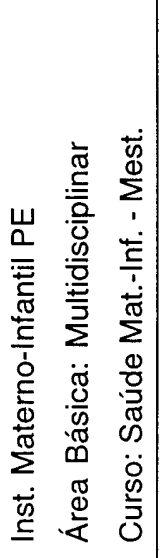 & 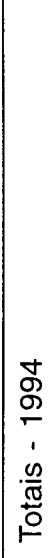 \\
\hline
\end{tabular}




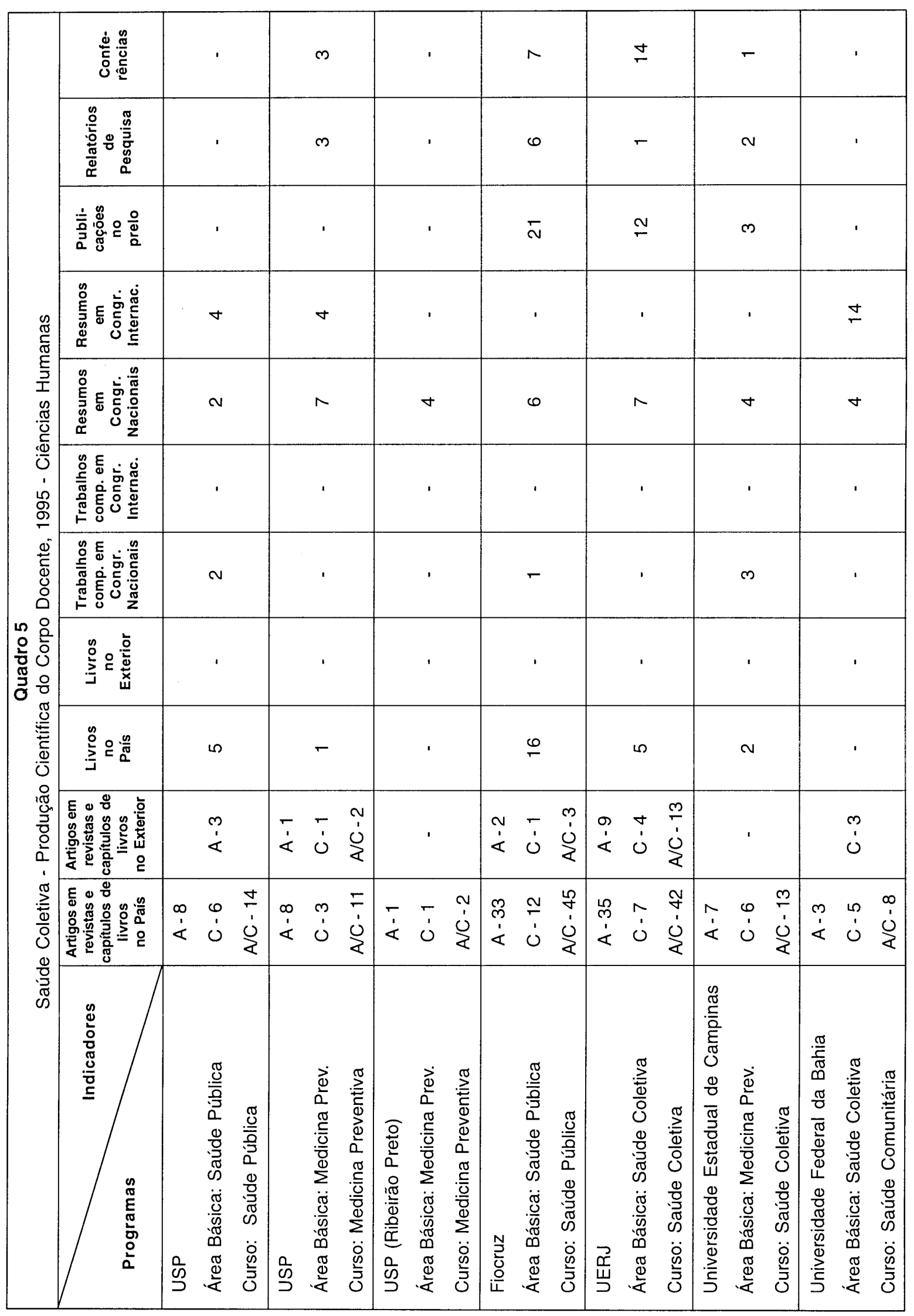




\begin{tabular}{|c|c|c|c|c|c|c|c|c|c|c|c|}
\hline ' & ' & & - & 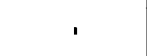 & ' & ' & $\sim$ & . & $\stackrel{\infty}{N}$ & 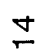 & $\mathscr{F}$ \\
\hline . & ' & ' & ' & ' & ' & $N$ & & ' & 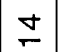 & $\sigma$ & $\stackrel{m}{N}$ \\
\hline مـ & $m$ & مـ & - & ' & ' & & & ' & 요 & $F$ & $\overline{0}$ \\
\hline ' & . & ' & ' & ' & . & ' & & . & $\approx$ & 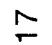 & बे \\
\hline$\sigma$ & - & $N$ & $m$ & $N$ & 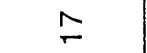 & ' & $\sigma$ & . & $\hat{\wedge}$ & జ్ర & \& \\
\hline . & ' & - & ' & ' & ' & . & . & , & - & , & - \\
\hline ' & ' & $m$ & & ' & ' & ' & ' & ' & $\sigma$ & $\stackrel{m}{\longrightarrow}$ & 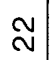 \\
\hline . & ' & ' & 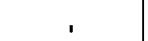 & , & . & . & 1 & ' & . & , & . \\
\hline ' & & ' & - & ' & $\bar{s}$ & ' & & ' & $\bar{m}$ & $\stackrel{ম}{N}$ & م \\
\hline ' & $\begin{array}{ccc}- & N & 3 \\
\dot{1} & 1 & \dot{0} \\
& 0 & 0\end{array}$ & ' & $r$ & ' & $\bar{⿱} \bar{\alpha}$ & ' & ' & & $\stackrel{\text { N }}{\text { s. }}$ & $\stackrel{\infty}{\sim}$ & $\hat{f}$ \\
\hline $\bar{\alpha}$ & i & $\begin{array}{l}N \\
\dot{1}\end{array}$ & 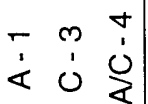 & & $\begin{array}{l}\infty \\
\dot{1} \\
\dot{0}\end{array}$ & ' & $\overline{1}$ & $\bar{\alpha}$ & 음 & $\stackrel{\stackrel{L}{m}}{\longrightarrow}$ & $\begin{array}{l}\stackrel{L}{\infty} \\
\stackrel{\infty}{N}\end{array}$ \\
\hline 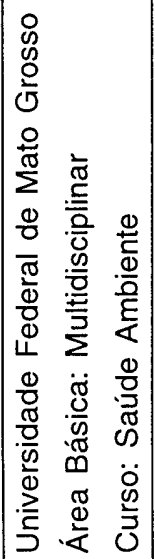 & 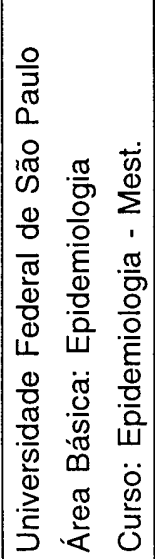 & 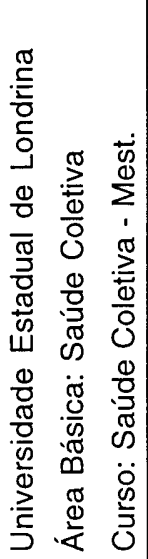 & 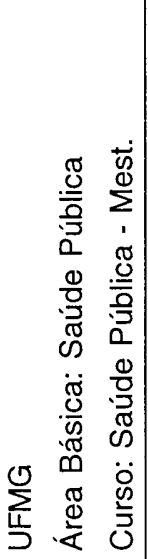 & 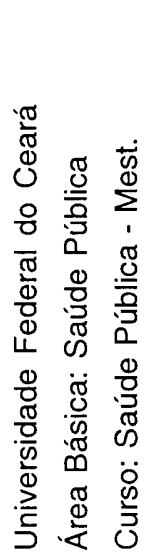 & 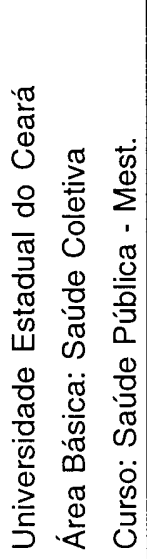 & 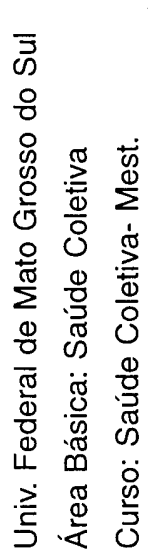 & 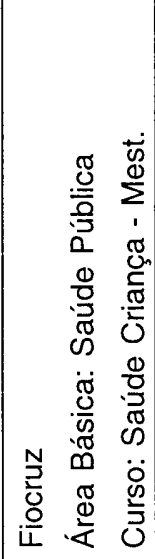 & 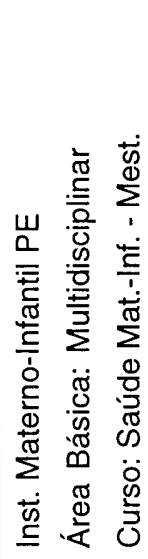 & 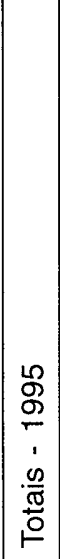 & 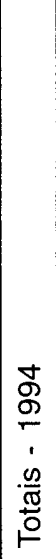 & 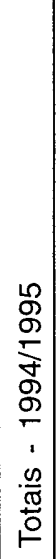 \\
\hline
\end{tabular}




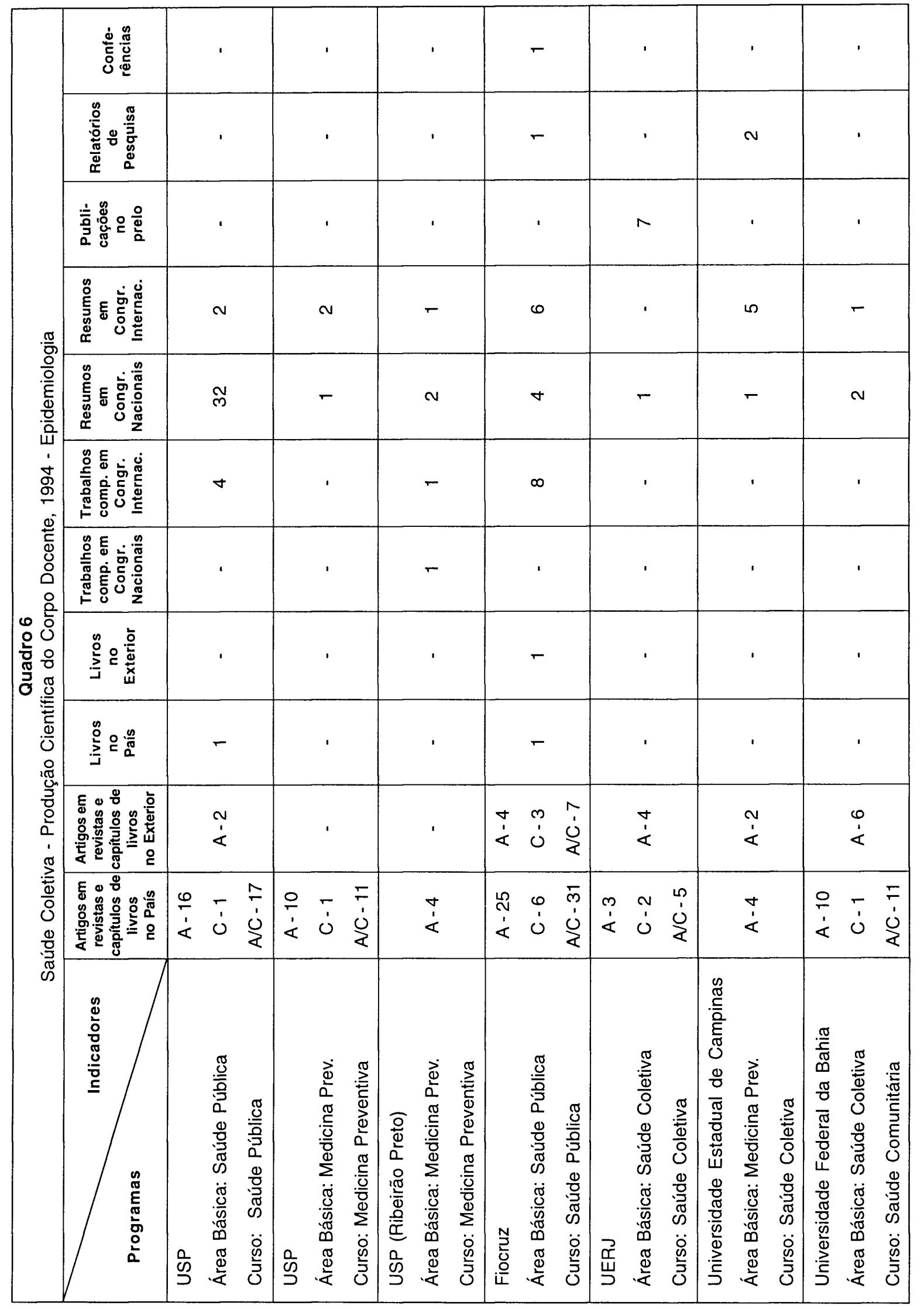




\begin{tabular}{|c|c|c|c|c|c|c|c|c|c|}
\hline . & $m$ & ' & $m$ & ' & 1 & ' & $\nabla$ & ' & $\mp$ \\
\hline . & $m$ & ' & ' & . & & $r$ & ' & ' & $r$ \\
\hline ' & ' & - & - & ' & ' & ' & $\sim$ & ' & $\mp$ \\
\hline ' & $\stackrel{\varphi}{\underline{1}}$ & . & $\cong$ & $N$ & ' & ' & ' & ' & f \\
\hline ' & ల్ & in & m & N & ' & 우 & م) & $m$ & $\stackrel{\widetilde{N}}{\mathrm{~N}}$ \\
\hline ' & ' & & ' & ' & ' & ' & ' & ' & $\stackrel{m}{-}$ \\
\hline . & - & ' & ' & . & ' & ' & $\mathcal{F}$ & . & g \\
\hline . & ' & ' & ' & ' & ' & ' & ' & ' & - \\
\hline ' & $r$ & $\tau$ & ' & . & , & ' & ' & ' & $\checkmark$ \\
\hline ' & $\begin{array}{lll}= & - & \frac{1}{1} \\
\dot{\alpha} & \dot{0} & \dot{3}\end{array}$ & $\overline{\dot{\alpha}}$ & $\begin{array}{l}m \\
\dot{1} \\
<\end{array}$ & $\begin{array}{l}m \\
\dot{1} \\
\dot{1}\end{array}$ & & ' & $\begin{array}{l}? \\
\dot{1} \\
<\end{array}$ & ' & $\stackrel{m}{\&}$ \\
\hline ' & 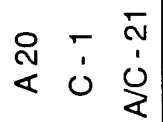 & $\begin{array}{l}? \\
\dot{\alpha} \\
\dot{<}\end{array}$ & $\begin{array}{lll}+ & N & 0 \\
\dot{\alpha} & 0 & \dot{1} \\
& 0 & \dot{8}\end{array}$ & $\begin{array}{lll}m & 0 & 0 \\
1 & 1 & 1 \\
< & 0 & 0\end{array}$ & ' & ' & $\begin{array}{l}N \\
\dot{\alpha}\end{array}$ & $\begin{array}{lll}\forall & N & 0 \\
1 & 1 & \vdots \\
< & 0 & 2\end{array}$ & $\stackrel{\mathcal{N}}{\sim}$ \\
\hline 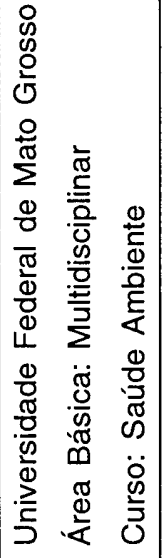 & 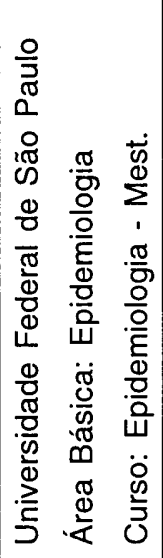 & 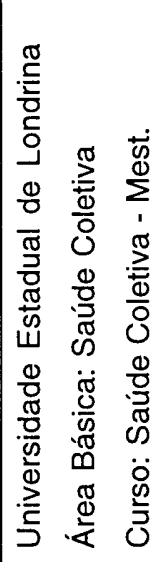 & 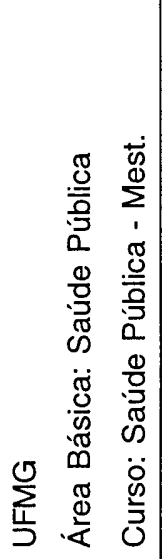 & 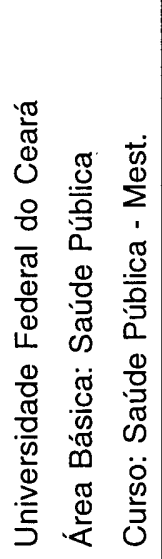 & 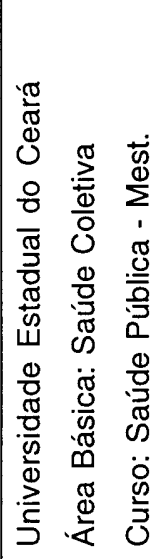 & 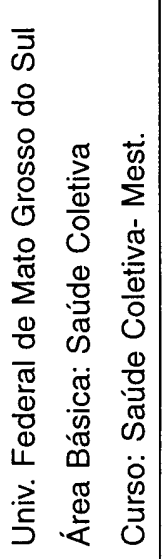 & 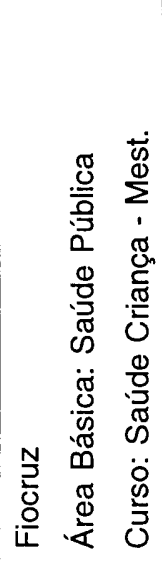 & 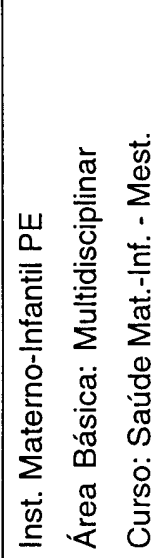 & 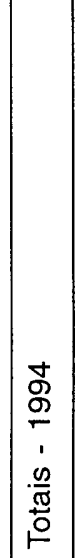 \\
\hline
\end{tabular}




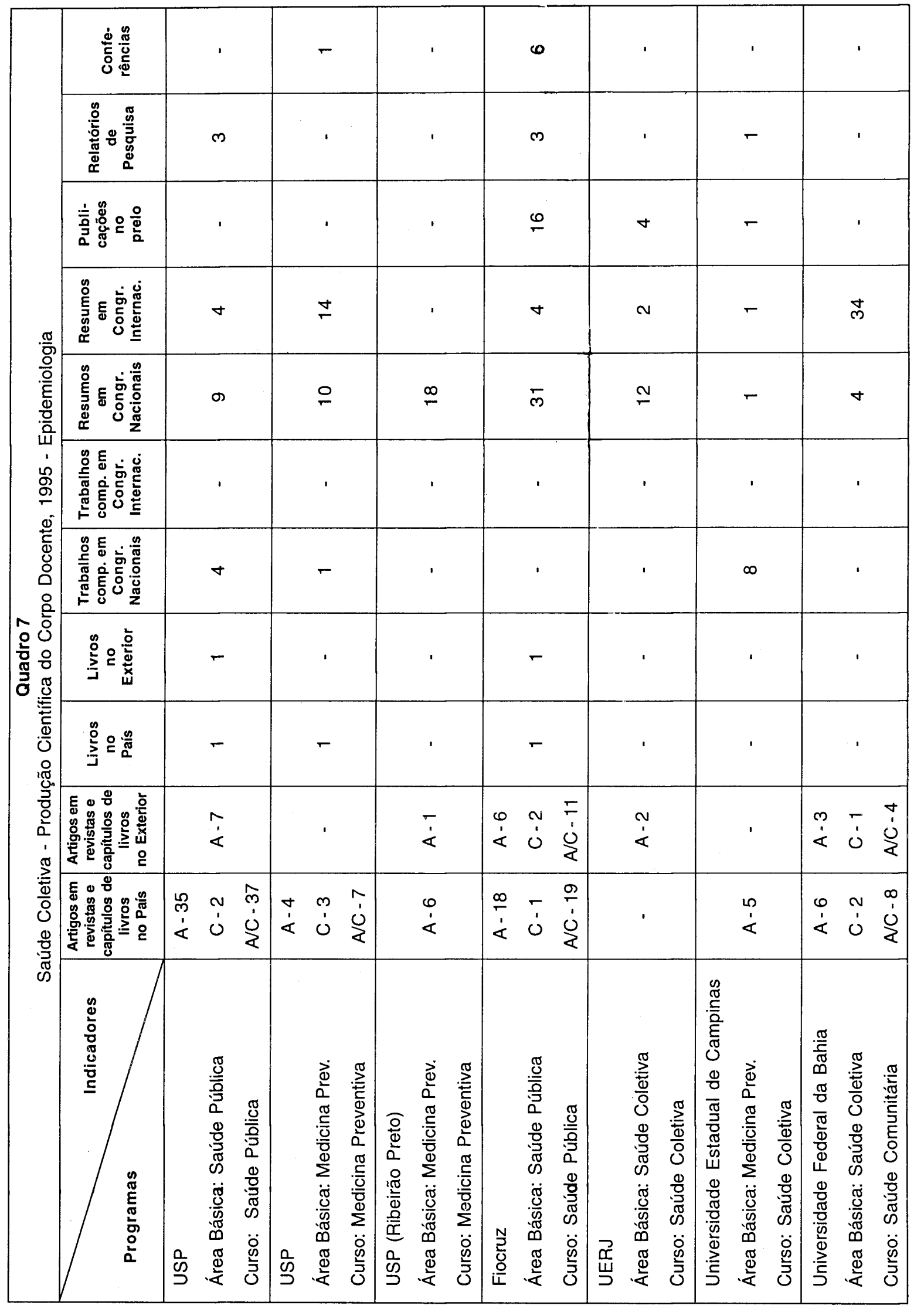




\begin{tabular}{|c|c|c|c|c|c|c|c|c|c|c|c|}
\hline ' & (n) & $N$ & $\sim$ & ' & ' & ' & $\sigma$ & ' & $\stackrel{L}{\sim}$ & $=$ & 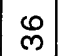 \\
\hline ' & ' & ' & ' & ' & & $r$ & m & ' & $\mp$ & 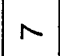 & $\stackrel{\infty}{\sim}$ \\
\hline$\stackrel{\sim}{\sim}$ & $\stackrel{60}{\leftarrow}$ & ' & 10 & ' & ' & $N$ & ' & $\sim$ & is & $=$ & $\infty$ \\
\hline ' & 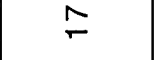 & ' & $\nabla$ & ' & ' & $\nabla$ & ' & ' & $\underset{\infty}{\forall}$ & f & $\bar{m}$ \\
\hline$\stackrel{+}{N}$ & $\stackrel{ \pm}{N}$ & $m$ & $\wedge$ & $\stackrel{\nabla}{ }$ & $\nabla$ & $r$ & $\stackrel{10}{m}$ & ' & $\stackrel{\hat{\sigma}}{-}$ & $\stackrel{\stackrel{M}{N}}{N}$ & i \\
\hline ' & ' & $r$ & ' & ' & ' & ' & $\tau$ & ' & $\sim$ & $\stackrel{m}{2}$ & $\stackrel{10}{\sim}$ \\
\hline- & ' & ' & ' & ' & ' & ' & ' & . & $\stackrel{+}{+}$ & g & m \\
\hline ' & ' & ' & ' & ' & ' & ' & ' & ' & $N$ & - & $m$ \\
\hline ' & - & ' & ' & ' & $m$ & ' & ' & & $\Lambda$ & $\sigma$ & $\mp$ \\
\hline ' & $\begin{array}{lll}\infty & - & 9 \\
1 & 1 & \vdots \\
< & 0 & z\end{array}$ & ' & $\begin{array}{l}\dot{I} \\
\dot{\alpha}\end{array}$ & ' & ' & ' & ' & - & $\hat{f}$ & $\mathscr{q}$ & ৪ \\
\hline$\sim$ & 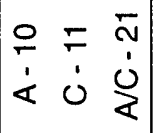 & $\bar{⿱}<$ & $\begin{array}{l}N \\
\dot{\alpha} \\
<\end{array}$ & $\begin{array}{l}\dot{H} \\
\dot{\alpha}\end{array}$ & ' & ' & $\begin{array}{lll}9 & \text { N } \\
\dot{<} & 0 & \vdots \\
\dot{1} & 0 & 0\end{array}$ & $\infty$ & $\stackrel{\text { లె }}{\sim}$ & लै & $\stackrel{+}{\stackrel{N}{N}}$ \\
\hline 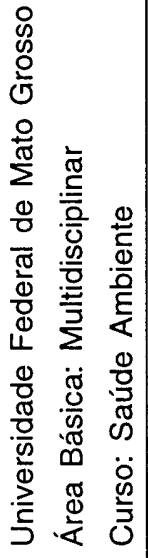 & 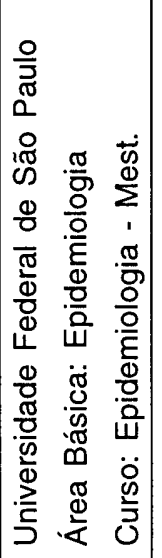 & 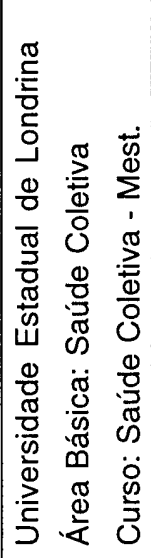 & 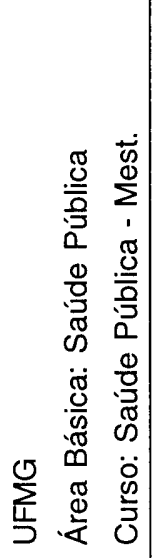 & 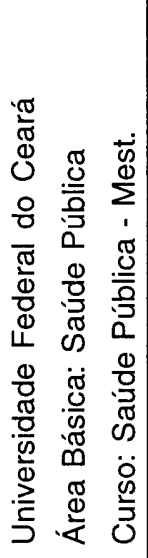 & 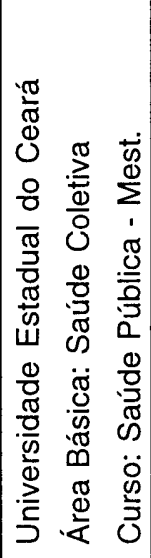 & 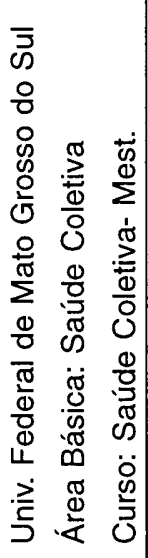 & 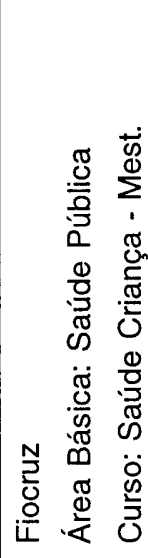 & 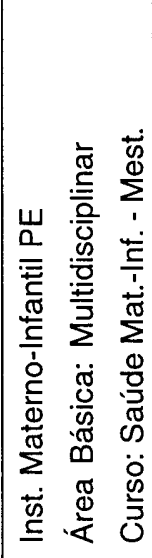 & 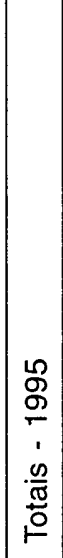 & 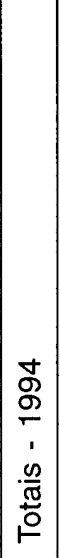 & 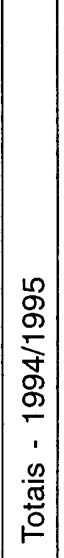 \\
\hline
\end{tabular}




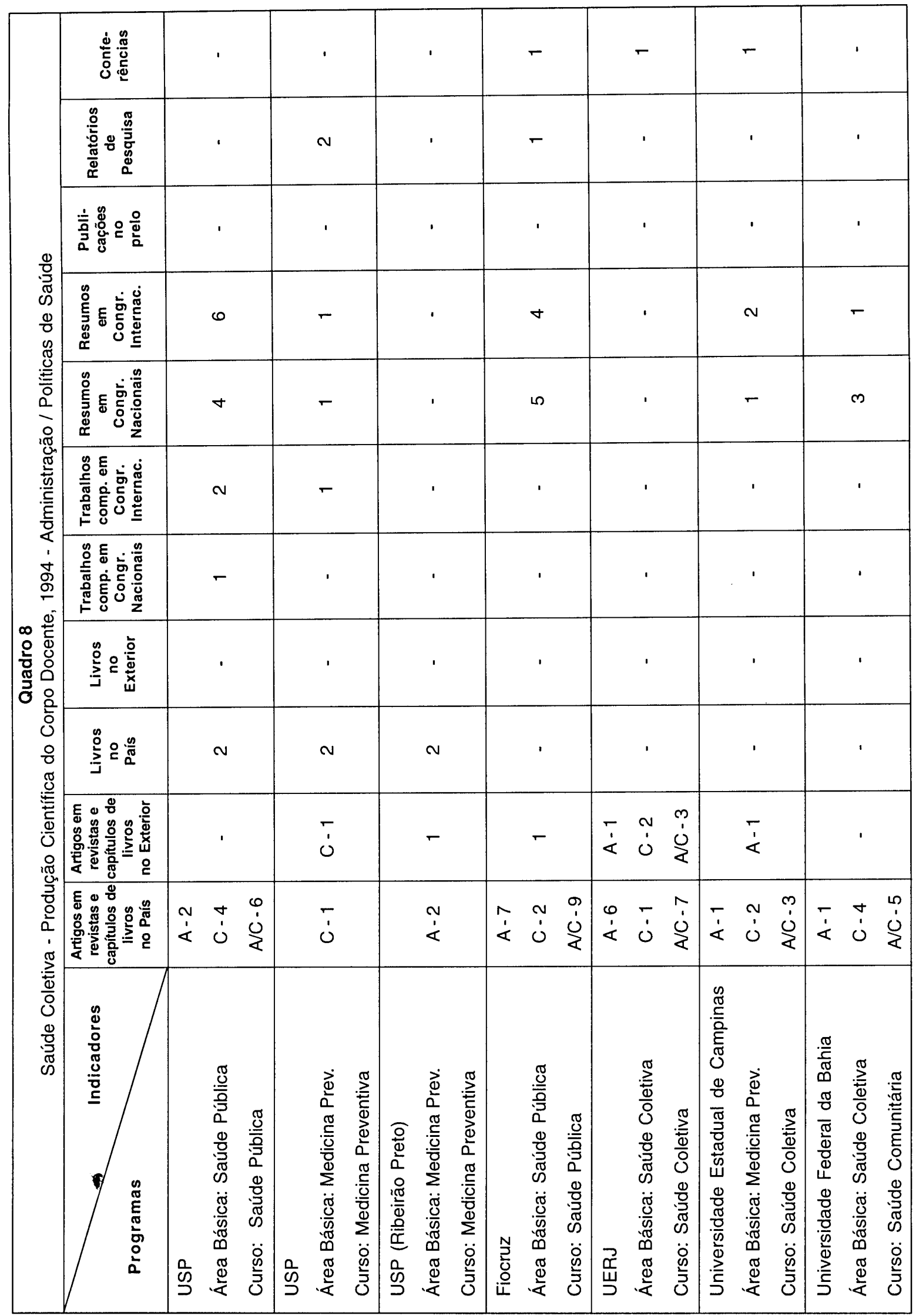




\begin{tabular}{|c|c|c|c|c|c|c|c|c|c|}
\hline & . & ' & ' & ' & ' & & & , & $m$ \\
\hline ' & & ' & - & ' & & - & ' & & in \\
\hline ' & ' & $\sim$ & $\nabla$ & ' & ' & ' & ' & & 0 \\
\hline ' & ' & ' & ' & ' & ' & ' & ' & ' & $\underset{\square}{ }$ \\
\hline ' & ' & $m$ & ' & $m$ & ' & $\stackrel{m}{-}$ & ' & ' & m \\
\hline ' & ' & ' & ' & ' & ' & ' & ' & ' & $m$ \\
\hline ' & ' & ' & ' & ' & ' & ' & $m$ & i & $\theta$ \\
\hline ' & & ' & ' & ' & ' & ' & ' & I & ' \\
\hline ' & ' & - & ' & ' & ' & ' & ' & ' & 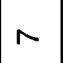 \\
\hline ' & ' & $\bar{c}$ & & ' & ' & ' & $\bar{c}$ & ' & $\sigma$ \\
\hline ' & $\bar{⿱} \dot{\alpha}$ & $\begin{array}{l}m \\
1 \\
<\end{array}$ & ' & ' & ' & ' & & ' & $\hat{m}$ \\
\hline 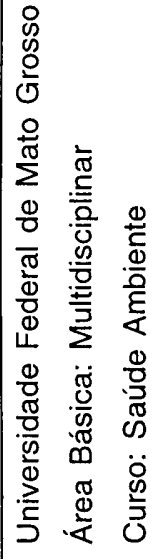 & 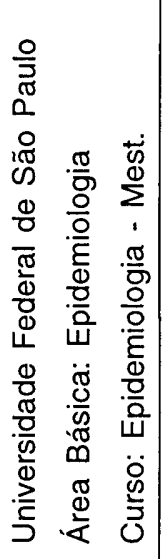 & 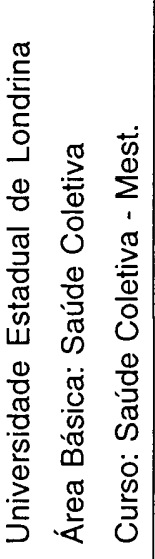 & 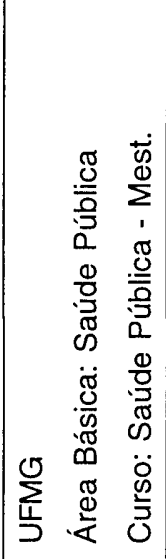 & 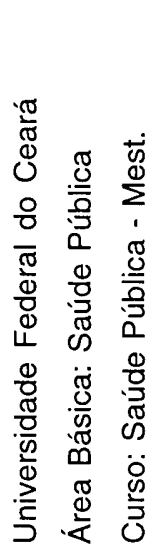 & 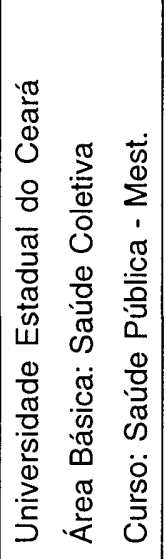 & 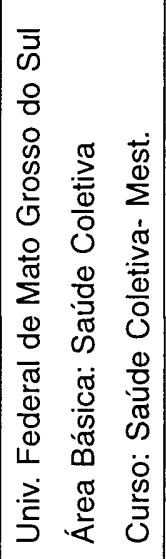 & 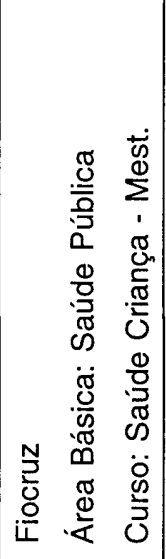 & 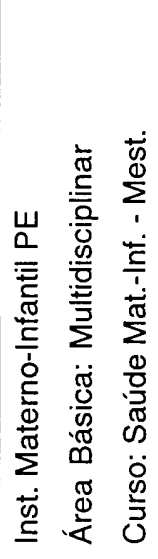 & 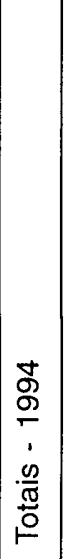 \\
\hline
\end{tabular}




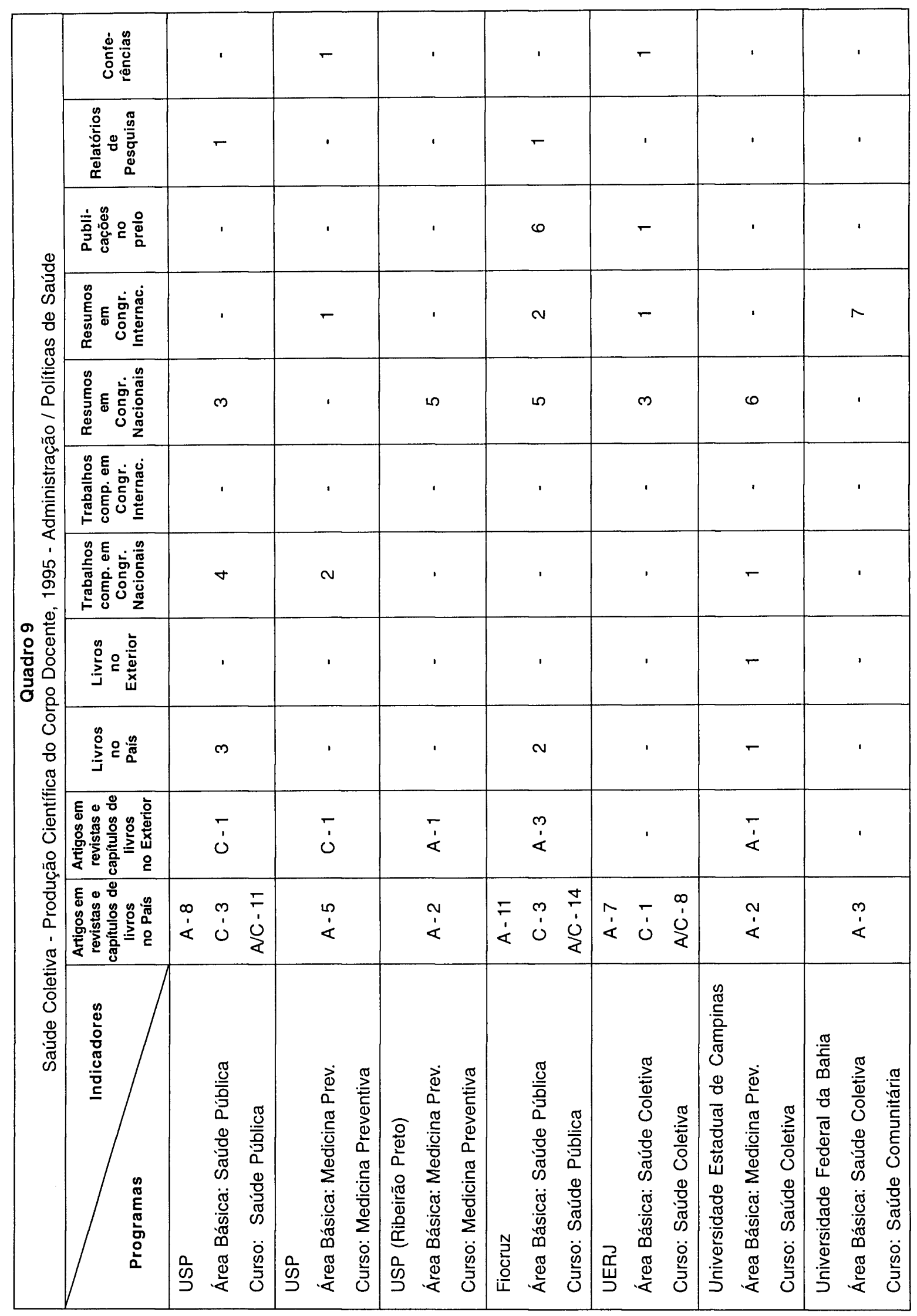




\begin{tabular}{|c|c|c|c|c|c|c|c|c|c|c|c|}
\hline & ' & ' & ' & & ' & ' & ' & & $\sim$ & $m$ & ما \\
\hline & & ' & ' & & ' & ' & 1 & ' & $\sim$ & in & $r$ \\
\hline & $N$ & - & - & ' & ' & ' & ' & ' & $=$ & 0 & 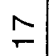 \\
\hline ' & - & $m$ & ' & ' & & ' & ' & ' & $\stackrel{2}{\sim}$ & $\stackrel{\nabla}{\leftarrow}$ & $\stackrel{D}{N}$ \\
\hline$N$ & $N$ & $m$ & ' & ' & $m$ & $N$ & $\sim$ & ' & $\ddot{m}$ & ల్ల & 8 \\
\hline ' & ' & ' & ' & ' & ' & ' & ' & ' & ' & $m$ & $m$ \\
\hline ' & ' & ' & ' & ' & ' & ' & ' & ' & 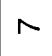 & $\theta$ & $\mp$ \\
\hline ' & ' & ' & ' & ' & ' & ' & ' & ' & $r$ & ' & $\tau$ \\
\hline ' & ' & . & ' & ' & - & ' & ' & ' & $\Lambda$ & $\Lambda$ & $\stackrel{\nabla}{\tau}$ \\
\hline ' & ' & r & $\stackrel{N}{i}$ & ' & ' & & - & . & 으 & 0 & $\stackrel{\sigma}{-}$ \\
\hline$\overline{\dot{\alpha}}$ & ' & $\begin{array}{l}m \\
1 \\
<\end{array}$ & $\frac{1}{<}$ & ' & $\bar{c}$ & & $\stackrel{N}{\stackrel{\alpha}{<}}$ & & న్ & $\hat{m}$ & ৪ \\
\hline 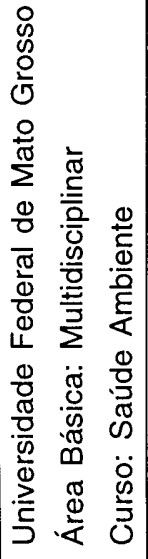 & 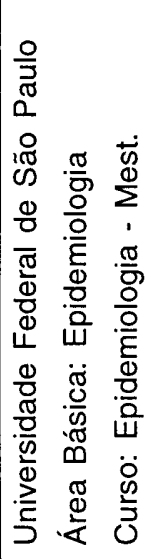 & 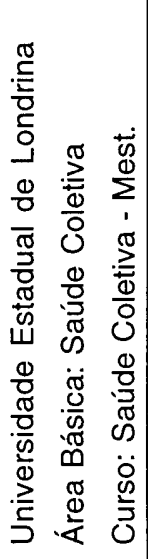 & 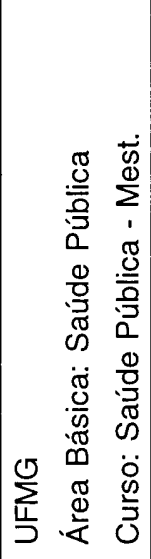 & 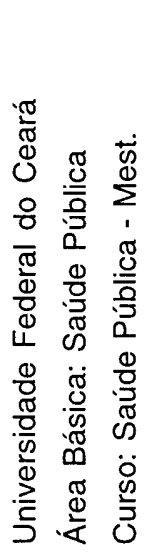 & 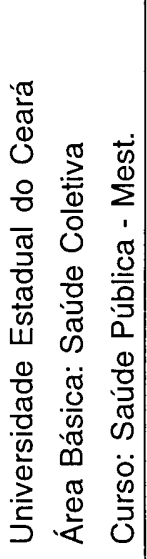 & 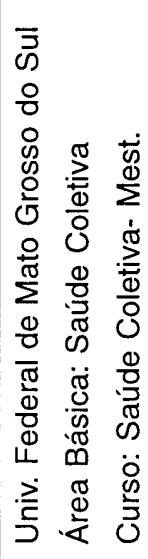 & 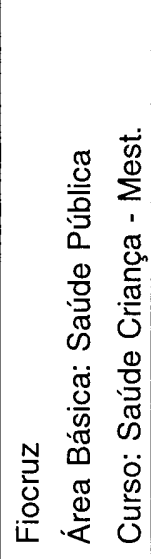 & 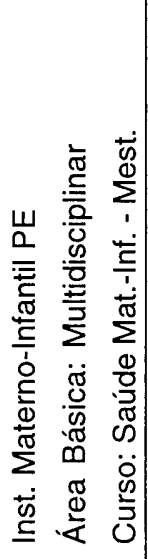 & 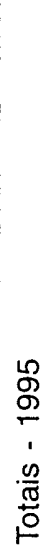 & 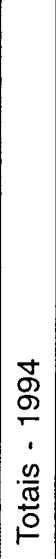 & 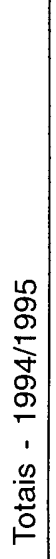 \\
\hline
\end{tabular}




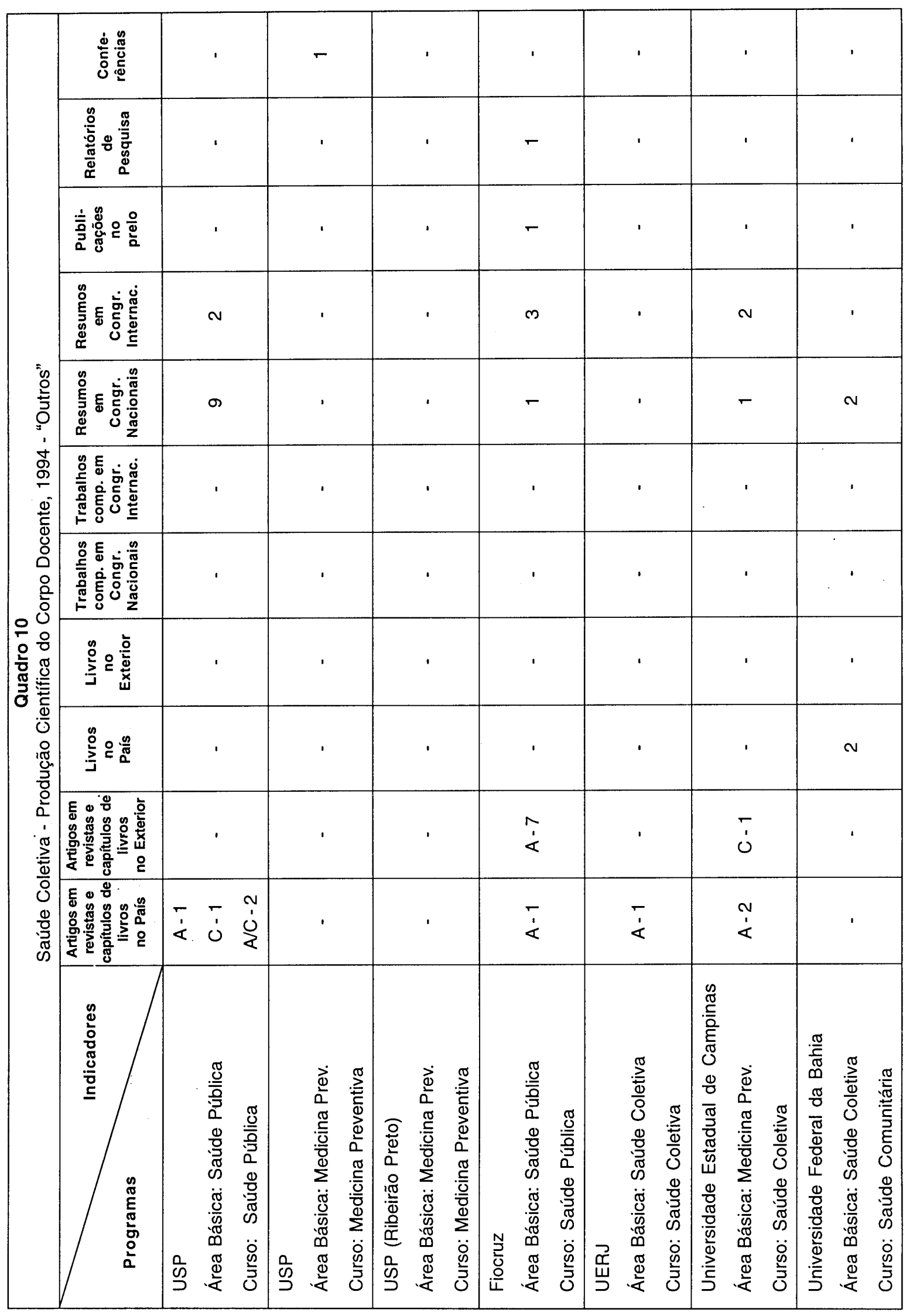




\begin{tabular}{|c|c|c|c|c|c|c|c|c|c|}
\hline . & . & & . & & . & . & , & , & - \\
\hline & ' & & ' & & ' & & ' & ' & - \\
\hline . & ' & - & N & ' & ' & ' & . & . & $\theta$ \\
\hline ' & $\theta$ & ' & . & ' & ' & ' & ' & ' & $\mp$ \\
\hline . & - & $m$ & I & $m$ & ' & - & ' & ' & $\overline{\mathrm{N}}$ \\
\hline . & 1 & ' & ' & ' & & ' & ' & & . \\
\hline ' & ' & . & ' & ' & . & ' & $N$ & . & $\sim$ \\
\hline ' & ' & ' & ' & ' & . & ' & . & , & ' \\
\hline ' & ' & ' & . & 1 & . & . & . & ' & $N$ \\
\hline ' & $\bar{c}$ & & ' & & ' & & $\bar{\alpha}$ & ' & 음 \\
\hline ' & ' & & $\overline{4}$ & ' & ' & & $\bar{\alpha}$ & ' & $\infty$ \\
\hline 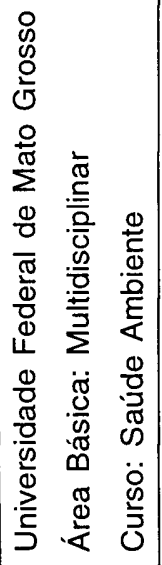 & 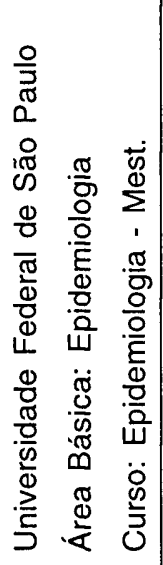 & 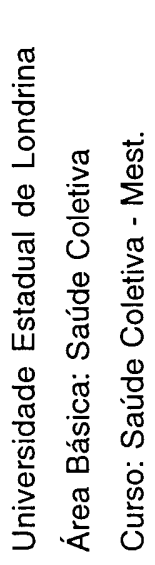 & 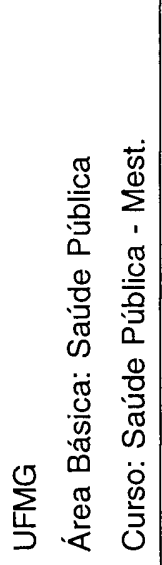 & 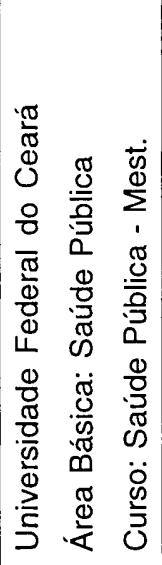 & 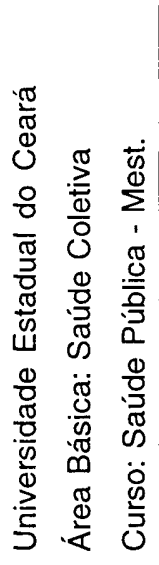 & 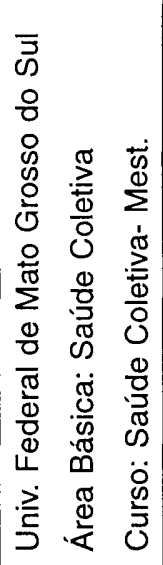 & 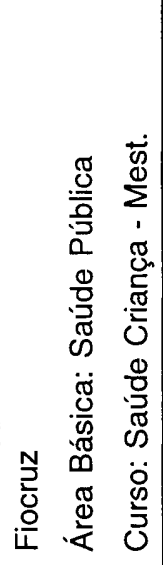 & 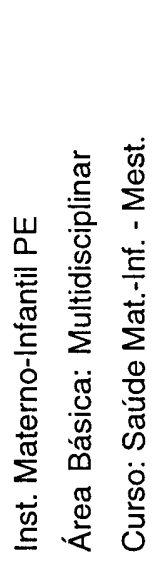 & 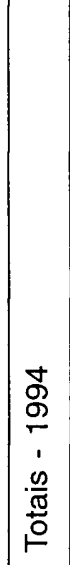 \\
\hline
\end{tabular}




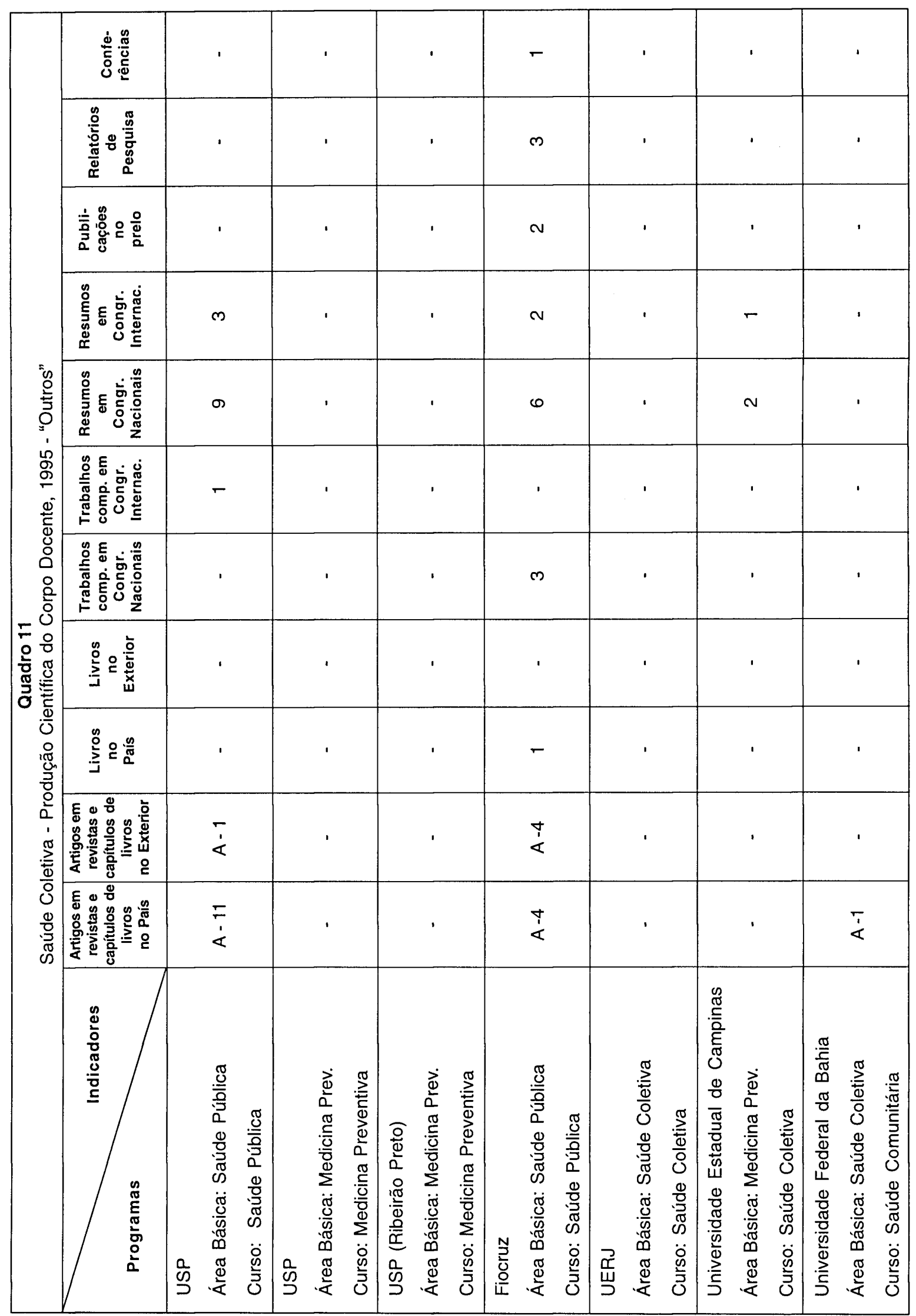




\begin{tabular}{|c|c|c|c|c|c|c|c|c|c|c|c|}
\hline & & ' & ' & & & 1 & & . & - & - & $N$ \\
\hline ' & ' & ' & ' & ' & & ' & & ' & $m$ & - & $\nabla$ \\
\hline . & . & - & ' & ' & ' & ' & ' & ' & $\sigma$ & $\nabla$ & $\stackrel{m}{\longrightarrow}$ \\
\hline ' & - & - & ' & ' & & & & ' & $\stackrel{9}{=}$ & ' & $\stackrel{\sim}{N}$ \\
\hline 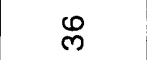 & ' & $\sim$ & ' & - & $r$ & ' & . & ' & $\stackrel{\infty}{\infty}$ & $\bar{N}$ & $\stackrel{R}{\Gamma}$ \\
\hline ' & ' & - & ' & ' & ' & ' & ' & ' & $N$ & ' & $N$ \\
\hline . & ' & ' & ' & ' & ' & & ' & ' & $m$ & $N$ & م \\
\hline ' & ' & & . & ' & ' & & ' & & ' & ' & ' \\
\hline N & ' & ' & ' & ' & ' & ' & ' & ' & $m$ & $N$ & م \\
\hline $\begin{array}{l}+ \\
\dot{\alpha}\end{array}$ & $\begin{array}{l}\dddot{N} \\
\ll\end{array}$ & & ' & ' & . & ' & ' & & $\mp$ & 으 & $\bar{N}$ \\
\hline $\bar{\alpha}$ & $\bar{\alpha}$ & & ' & ' & $\bar{\alpha}$ & , & $\bar{\alpha}$ & & $\stackrel{\sim}{\text { D }}$ & $\infty$ & $\stackrel{\infty}{\sim}$ \\
\hline 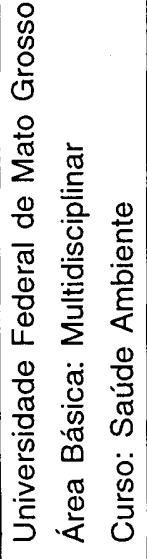 & 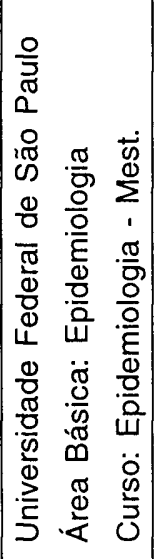 & 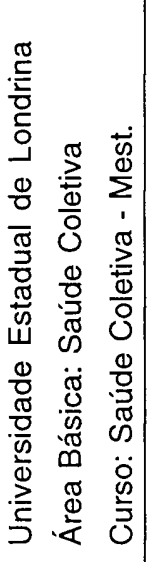 & 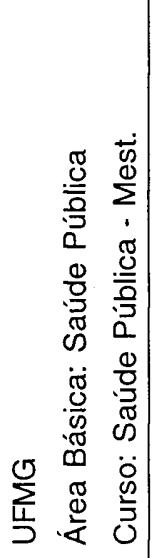 & 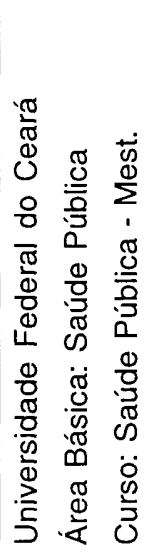 & 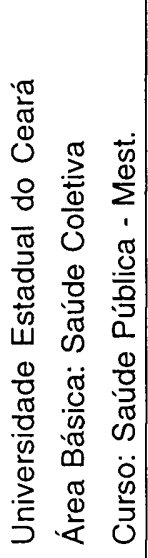 & 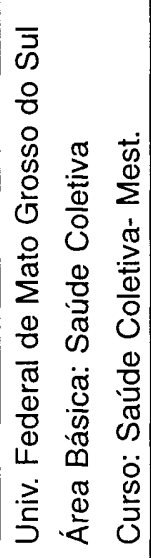 & 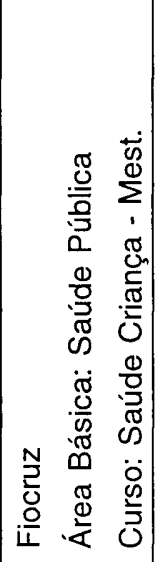 & 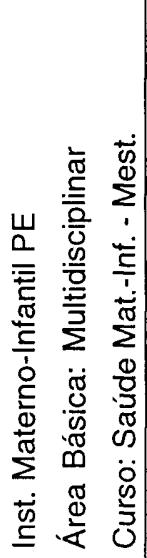 & 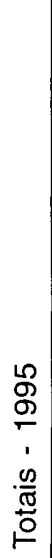 & 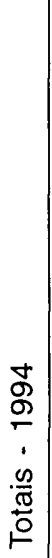 & 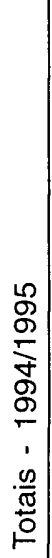 \\
\hline
\end{tabular}


tiva, com eles interagindo e produzindo mudanças, com relativa rapidez, apresentando no biênio crescimento em todos os indicadores de produção, com exceção do indicador trabalhos completos publicados em congressòs (Quadro 5).

A subárea de Planejamento e Administração em Saúde apresenta, como era esperado, um perfil mais "técnico", com o predomínio de produtos como relatórios e comunicações em congressos nacionais e internacionais, além de livros (em 1995). Aqui deve ser mencionado, para não se ter uma falsa idéia de improdutividade desta subárea, que Planejamento \& Administração não constitui, como as outras, uma área disciplinar; trata-se muito mais de um campo teórico-prático de intervenção de várias disciplinas (Economia, Administração, Epidemiologia, Sociologia, Política, Demografia, para mencionar as principais) aplicado à gestão das políticas e instituições de saúde. Sendo um campo multidisciplinar, em geral sua produção "migra" para as demais subáreas, sobretudo a de Ciências Humanas. Grande parte dos docentes de Planejamento e Administração em Saúde são de fato cientistas sociais que produzem para a área, mas não na área. A produção específica da área de Planejamento e Administração é, em grande parte, técnica (projetos e relatórios técnicos de implementação, gestão e avaliação de políticas, serviços e instituições de saúde). Por isso, os indicadores teriam de levar em conta o "produto esperado" da subárea que, nesse caso, se enquadraria mais em produção técnica, ou artística, e isto não deveria ser pontuado de maneira a prejudicar a área.

No entanto, um grande esforço no sentido de assegurar maior freqüência e qualidade de produção em relação aos indicadores tradicionais (artigos em revistas nacionais e internacionais, capítulos de livros e livros) deve ser empreendido por esta subárea, no sentido de equilibrá-la junto à produção de
Ciências Humanas em Saúde e Epidemiologia. No biênio 1994-95, o desequilíbrio é flagrante (Quadros 5, 7 e 9).

A subárea de Epidemiologia apresentase como a mais equilibrada no biênio, considerando-se a totalidade dos indicadores (Quadros 4 a 9). Tanto em artigos e capítulos de livros, como em congressos nacionais e internacionais (resumos e textos completos publicados, conferências) esta clássica área apresenta grande vitalidade, tematizando em suas linhas de pesquisa as mais variadas questões, sejam elas da atualidade (relativas à terceira idade, às doenças crônicodegenerativas, às doenças do trabalho, ou à metodologia e modelos em epidemiologia), como as tradicionais da área, ligados à saúde materno-infantil, à saúde mental, às endemias e epidemias, como a epidemia pelo HIV/AIDS. Uma tendência à interdisciplinaridade póde ser notada em alguns programas, através de publicações e comunicações em Congressos.

A mesma diversidade e atualidade temática pode ser observada também na subárea de Ciências Humanas: as linhas de pesquisa e a produção senso estrito (artigos, capítulos etc.) tendem a trabalhar temas como a AIDS, as doenças sexualmente transmissíveis, a sexualidade e as práticas reprodutivas, em estudos sócio-antropológicos; além disso, estudos sócio-políticos concernentes à violência, à terceira idade, à construção do S.U.S., à educação e à participação nas decisões sobre serviços de saúde tendem a se apresentar em vários dos programas com maior tradição na área, geralmente em perspectiva pluridisciplinar. Estas linhas podem aparecer também na subárea de Planejamento e Administração em Saúde que não é, como já afirmamos, uma subárea disciplinar, mas uma área teórico-prática de intervenção político-social.

Outros temas emergentes de investigação privilegiam a Filosofia, a História, a Ética e a Comunicação em suas relações com a saúde e a medicina. Concluindo, a 
produção do biênio, incluídas as linhas de pesquisa, aponta para um florescimento das disciplinas da Filosofia e das Ciências Humanas em geral no campo da Saúde Coletiva, inclusive nas subáreas da Epiclemiologia e do Planejamento e Administração. Aponta também, como afirmamos inicialmente, para a pujança do campo, no que concerne aos indicadores tradicionais de aferição da produção científica, ainda que na categoria "Outros" haja uma produção recente que merece um estudo posterior mais aprofundado, no sentido de acompanhar as novas fronteiras de expansão do campo, tanto do ponto de vista qualitativo como quantitativo.

De qualquer modo, uma dispersão de temas de pesquisa e de produção de trabalhos era esperável, na proporção mesma da importância e do polimorfismo de que se reveste o campo denominado Saúde Coletiva na sociedade atual. 